\title{
Colaborar para Produzir: Uma Avaliação Bibliométrica da Cooperação Acadêmico-Científica em Estudos de Administração sobre Cultura e Consumo'
}

\section{Cooperating pushes Publishing: A Bibliometric Survey about the Academic-scientific Cooperation in Administration Studies about Culture and Consumption}

Eduardo Santos Rocha Zafaneli, B.Sc.

Universidade Estácio de Sá

Mestrado em Administração e Desenvolvimento Empresarial (MADE)

Av. Presidente Vargas, 642, 22ํㅜ andar - Centro - CEP: 20071-001 - Rio de Janeiro - RJ eduardozafaneli@gmail.com

Elizabeth Paula Chaves Cantiello Machado, B.Sc.

Universidade Estácio de Sá

Mestrado em Administração e Desenvolvimento Empresarial (MADE)

Av. Presidente Vargas, 642, 22ํㅜ andar - Centro - CEP: 20071-001 - Rio de Janeiro - RJ

elizabethcantiello@gmail.com

Izabel Gerheim Villaça, B.Sc.

Universidade Estácio de Sá

Mestrado em Administração e Desenvolvimento Empresarial (MADE)

Av. Presidente Vargas, 642, 22ํㅜ andar - Centro - CEP: 20071-001 - Rio de Janeiro - RJ

belgvillaca@gmail.com

Irene Raguenet Troccoli, D.Sc.

Universidade Estácio de Sá

Mestrado em Administração e Desenvolvimento Empresarial (MADE)

Av. Presidente Vargas, 642, 22ํㅜ andar - Centro - CEP: 20071-001 - Rio de Janeiro - RJ

RESUMO

irene.troccoli@estacio.br

O conhecimento científico pode ser produzido de forma isolada ou compartilhada. Quando se dá a partir da colaboração entre pesquisadores, benefícios extras podem ser obtidos, tais como economia de tempo e de recursos financeiros e materiais. O presente artigo de abordagem quantitativa é um levantamento bibliométrico realizado nos trabalhos aprovados nos Enanpads do triênio 2009-11, específicos das seções Cultura e Consumo (em 2009 e 2011) e Consumo, Cultura e Grupos Sociais (em 2010), ambos da Divisão Acadêmica Marketing, no que tange à cooperação acadêmico-científica entre seus autores. Foram analisados nove aspectos: distribuições quantitativa dos trabalhos, de autores por artigo, por gênero de autores, por tipos de coautoria, por ordenação de autores, por forma de coautoria, por tipo de cooperação, e por instituições a que os autores estão afiliados. Os resultados comprovam que a coautoria é um evento assaz costumeiro no âmbito do levantamento. Dentre os achados mais relevantes destacam-se que quase metade da amostra revelou coautoria em nível de cooperação exclusivamente

\footnotetext{
1 Artigo recebido em 20.05.2013. Revisado pelos pares em 08.08.2013. Ajustado e Aceito para publicação em 12.08.2013. Recomendado para publicação por José Ribamar Marques de Carvalho (Editor Científico). Publicado em 15.09.2013. Instituição responsável UACC/CCJS/UFCG.
} 
interna, assim como a ampla preferência pela autoria dupla e a grande concentração geográfica das escolas participantes nas regiões sudeste e sul do País. Conclusões são tecidas a respeito e limitações naturais da pesquisa são indicadas. Ao final, sugestões para futuras pesquisas são apresentadas.

Palavras-Chave: Coautoria. Cultura. Consumo.

\begin{abstract}
Scientific knowledge can be produced by single authors or simultaneously by multiple authors. When the latter happens, additional benefits can be obtained, such as the saving of time and of financial and material resources. This quantitative article is a bibliometric survey about the articles presented at the 2009-11 Enanpads in the sections Culture and Consumption (in 2009 and 2011) and Consumption, Culture and Social Groups (in 2010), both belonging to the Marketing academic division, specifically in regard to academic and scientific cooperation among its authors. Nine quantitative aspects were analyzed: the distribution of the papers, the number of authors per article, the genre of the authors, the ordering of the authors' names, the types of co-authorship, the type of cooperation, and the institutions to which the authors are affiliated. Among the most important findings one notices the preference for dual authorship and for international cooperation, as well as the high concentration of authors in the southern and southeastern portions of Brazil. At the end, further researches are suggested.
\end{abstract}

Key-words: Coauthoship. Culture. Consumption.

\title{
1 INTRODUÇÃO
}

Com o advento da globalização e da pós-modernidade, as relações de consumo em todo mundo sofreram significativas transformações. Dentro deste contexto, temse observado uma importante participação da cultura como agente influenciador no processo de consumo de produtos e de serviços. Pode-se conceituar cultura como coloca Taylor (1903, apud LARAIA, 2000, p.25): "Cultura é todo complexo que inclui conhecimentos, crenças, arte, moral, leis, costumes ou qualquer outra capacidade ou hábitos adquiridos pelo homem como membro de uma sociedade".

Para corroborar com esta linha de pensamento, Cobra (2005, p.183) afirma que "A cultura é a mais importante determinante dos desejos de compra de uma pessoa. As pessoas crescem aprendendo a estabelecer valores, percepções e preferências, através do processo de socialização que envolve a família, os amigos e outros grupos de referência". Esta influência cultural nas relações de consumo é fortalecida principalmente pelas necessidades psicológicas, pessoais e sociais inerentes ao consumidor, que o levam a buscar satisfaze-las (SCHIFFMAN; KANUK, 2009).

Para Blackwell, Miniard e Engel (2005), algumas das mais importantes características influenciadas pela cultura são: sentido do eu e do espaço; comunicação e linguagem; vestuário e aparência; alimentação e hábitos alimentares; tempo e consciência de tempo; relacionamentos (família, organizações, governos etc.); valores e normas; crenças e atitudes; processos mentais e aprendizagem; e hábitos e práticas de trabalho. 
Também conhecidas como formas de compartilhamento cultural (SCHIFFMAN; KANUK, 2009), essas características de aculturamento são utilizadas principalmente pelo Marketing para influenciar comportamentos de consumo e estimular hábitos de compra. Principalmente no que tange à família e às mídias de massa, esta influência cultural cria, no indivíduo, uma predisposição para o consumo de produtos (DIAS, 2003) e estimula o ato de compra. A família possui tal influência devido aos vínculos emocionais que constrói entre seus integrantes e os comportamentos aprendidos, transmitidos de geração para geração (KEEGAN; GREEN, 2003).

Já as mídias de massa exercem sua influência baseadas na manifestação social conhecida como "cultura de massa". Composta de mídia, de Marketing e de publicidade, suas funções essenciais na sociedade moderna, industrial e capitalista incluem ser a instância que viabiliza este código ao comunicá-lo à sociedade. Para tanto, ela "[...] interpreta a produção, socializa para o consumo e nos oferece um sistema classificatório que permite ligar um produto a outro e todos juntos às nossas experiências de vida" (ROCHA, 2005, p. 137).

É neste espaço teórico que reside o interesse em se realizar levantamento bibliométrico relativo aos artigos aprovados nos Encontros Anuais da Associação Nacional de Pós-Graduação e Pesquisa em Administração (Enanpads) que tenham se situado em duas áreas específicas da Divisão Acadêmica de Marketing: a de Cultura e Consumo, e a de Cultura, Consumo e Grupos Sociais.

No caso, este levantamento teve o foco especificamente dirigido à coautoria, conceito que remete ao trabalho compartilhado, e se justifica pelo que dizem Maia e Caregnato (2008) quando enfatiza que no âmbito da ciência, a imagem do pesquisador isolado faz parte do passado, pois atualmente o processo de produção científica requer associações, negociações e estratégias para interligar o maior número de elementos possíveis. O compartilhamento de informações, a junção de competências e a união de esforços de pesquisadores na busca de metas em comum impulsionam a produção de conhecimento.

Este artigo se apresenta dividido em sete partes. Após esta introdução, é apresentada breve revisão bibliográfica sobre cultura e consumo, seguida de tópico específico sobre a bibliometria e sobre estudos realizados no Brasil utilizando esta técnica. Em seguida, há tópico sobre coautoria, seguido da apresentação dos procedimentos metodológicos utilizados e dos dados gerados pela pesquisa bibliométrica. O artigo é concluído com uma breve análise crítica destes dados, com a apresentação das limitações inerentes ao estudo realizado e com a apresentação de sugestões para pesquisas futuras. 


\section{REFERENCIAL TEÓRICO}

\subsection{CULTURA E CONSUMO}

Para Castilho, Rossi e Cavedon (2005), a cultura é um sistema simbólico, de significados partilhados pelos membros de uma determinada comunidade. Já o consumo seria

"[...] a própria arena em que a cultura é objeto de lutas que lhe conferem
forma. A dona-de-casa com sua cesta de compras chega em casa: reserva
algumas coisas para casa, outras para o marido e para as crianças; outras
ainda sãodestinadas ao especial deleite dos convidados. Quem ela convida
para a sua casa, que partes da casa abre aos estranhos e com que freqüência,
o que lhes oferece como música, bebida e conversa, essas escolhas exprimem
e geram cultura em seusentido mais geral" (DOUGLAS; ISHERWOOD,
2004, p. 103).

Ruscheinsky (2007) adiciona que a sociedade contemporânea, enquanto capaz de gerar impactos sobre o meio ambiente natural e construído, faz com que a abordagem do consumo, enquanto processo por etapas, sirva para traçar algumas das características predominantes desta mesma sociedade, “[...] muito embora se mostre frágil ao não considerar de modo satisfatório a enorme disparidade material e cultural entre os diversos grupos sociais, entre etnias e entre nações" (p. 76).

Assim é que os bens constituem oportunidade de dar matéria à cultura, e o fato de possuírem significado cultural pode ser evidente e às vezes oculto para os consumidores. Para Pena, Coutinho e Pépece (2010) isto ocorre porque, a partir do momento em que a cultura e o consumo são operados de forma conjunta, este último deixa de ser apenas um ato "comercial" para se tornar um sistema simbólico, através do qual a cultura expressa seus princípios, categoriais, ideais, valores, identidades e projetos.

Por outro lado, não se pode olvidar que o consumo é também um importante componente para a compreensão das identidades dos indivíduos, pois estes se comunicam e se constroem por meio dos significados atribuídos às suas posses (BELK, 1988). Assim, os objetos podem identificar indivíduos, grupos e culturas e, para tanto, constituem-se em suportes ou unidades textuais (MACHADO; PEREIRA, 2010).

É por isto que, através da perspectiva histórica, é possível observar como a cultura de massa contribui para a manutenção, para a reprodução e para a sobrevivência da sociedade de consumo em massa, conforme o papel da comunicação se revela fundamental por representar uma das principais instituições sociais da sociedade moderna (GONÇALVES, 2008). 


\subsection{BIBLIOMETRIA}

O estudo bibliométrico é uma técnica estatística e quantitativa de medição dos índices de produção do conhecimento científico, através da aplicação de técnicas matemáticas e estatísticas para descrever, quantificar e prognosticar aspectos bibliográficos de comunicação escrita. Esta técnica, também conhecida como Bibliometria, foi primeiramente mencionada por Hulme (1922), com sendo uma ferramenta de esclarecimento dos processos tecnológicos e científicos, por meio da contagem de documentos.

Posteriormente, esta categoria de estudo foi mencionada por vários autores como Otlet (1934), Gosnell (1944) e Raising (1962). Porém, foi através do artigo de Pritchard (1969) que a bibliometria passou a ser reconhecida como uma área de estudo que usa métodos estatísticos de investigação e de quantificação dos processos de comunicação escrita.

Sustentada por três pilares empíricos - Lei de Lotka (1926), Lei de Bradford (1934) e Leis de Zipf (1949) - a bibliometria desenvolveu-se como referencial no que tange à análise bibliográfica. A Lei de Lotka veio contribuir para este desenvolvimento, tratando da produtividade científica de autores, apontando as diferentes proporções de produção da literatura científica entre os pequenos e grandes produtores. Já a Lei de Bradford trouxe sua contribuição no campo da produtividade de periódicos, analisando a dispersão da literatura periódica científica. Por fim, as Leis de Zipf agregaram conhecimento no que se refere ao estudo e à análise de frequência de uso de palavras em determinados textos.

\subsubsection{ESTUDOS BIBLIOMÉTRICOS PRODUZIDOS NO BRASIL}

A elaboração de estudos bibliométricos no Brasil é intensa, pela utilidade que este tipo de levantamento implica. Por exemplo, apenas dentro dos Enanpads, entre 2000 e 2011, 194 estudos se autodenominaram bbiliométricos (SPLITTER; ROSA; BORBA, 2012). Por outro lado, pela sua própria diversidade, não é possível apresentar um panorama completo desta atividade em espaço curto, embora quatro exemplos pontuais sirvam para comprovar esta elevada utilidade.

Araújo e Alvarenga (2011), por exemplo, avaliaram a inserção dos estudos bibliométricos na pesquisa científica da pós-graduação no Brasil entre 1987 e 2007, a partir da analise de teses e dissertações que abordaram aspectos de estudos bibliométricos. Seus resultados relatados a partir de amostra de 82 trabalhos de pesquisa defendidos no País "[...] apresentam uma vasta produção de estudos cienciométricos no Brasil, distribuídos pelas mais variadas áreas de conhecimento" (p. 66).

Pizzani, Silva e Hossne (2010), por sua vez, utilizaram a análise bibliométrica para avaliarem a produção científica em Bioética após 40 anos do nascimento deste 
campo da ciência. Seu levantamento envolveu 5.334 estudos, cujas temáticas mais abordadas foram ética médica, genoma humano, clonagem, aborto e eutanásia.

Já Mugnaini, Jannuzzi e Quonian (2004) apresentam e analisam indicadores bibliométricos da produção científica e tecnológica de pesquisadores brasileiros ao longo dos anos de 1990, computados a partir da base francesa Pascal. Os resultados mostraram aumento expressivo desta produção brasileira, assim como sua internacionalização, corroborando outros estudos, baseados em outros indicadores em ciência e tecnologia ou mesmo em indicadores bibliométricos derivados das bases da companhia publicadora de bases de dados Institute for Scientific Information.

Finalmente, Hayashi et al. (2007) utilizaram a técnica para analisar a produção científica acadêmica sobre a educação jesuítica no Brasil colonial. Sua conclusão é que, a partir dos anos de 1990, esta produção aumentou fortemente, representada nas bibliotecas digitais brasileiras por 187 dissertações, 83 teses de doutorado e 5 teses de livre docência.

Por outro lado, vale salientar que nem todo trabalho dito bibliométrico cumpre as exigências mínimas para alcançar tal qualificação. A análise de Splitter, Rosa a Borba (2012), especificamente realizada em amostra de 194 artigos no ambiente dos Enanpads entre os anos 2000 e 2011, indicou que, além de quase um terço deles não apresentar nenhuma das 12 características de um levantamento realmente bibliométrico, "[...] do restante, aproximadamente $60 \%$ têm de uma a no máximo quatro características [indicando que] nenhum dos trabalhos analisados poderia ser efetivamente considerado bibliométrico" (p. 1).

\subsection{COAUTORIA}

Os primeiros registros de iniciativas acadêmicas baseadas na coautoria são datados de 1939, com a produção de uma equipe de pesquisadores composta predominantemente de matemáticos franceses, divulgada sob o pseudônimo de Bourbaki (MEADOWS, 1999). Mas foi após a Segunda Guerra Mundial que a coautoria ganhou força, principalmente com projetos e pesquisas nas áreas de ciência espacial e de física nuclear. Seu ponto máximo de desenvolvimento foi alcançado na sociedade pós-moderna, conforme a colaboração intelectual entre pesquisadores passou a ser mais comum.

Vários fatores alavancaram este fenômeno, conforme Maia e Caregnato (2008), com destaque para a economia de tempo e de recursos financeiros e materiais - e o consequente estímulo por parte das agências financiadoras de pesquisas - assim como a consecutiva formação de boas, eficientes e produtivas equipes de trabalho.

Tais mudanças no contexto da investigação científica têm colocado a publicação de pesquisas em destaque no desenvolvimento científico e, especificamente, na estrutura de avaliação dos pesquisadores (ACEDO et al., 2006). Neste panorama, a 
coautoria tem sido vista como uma prática que facilita a divisão do trabalho (SILVA et al., 2006), principalmente no que se refere à redução de custos de alguns equipamentos ou softwares para análise de dados, e ao estímulo à multidisciplinaridade (LETA; CRUZ, 2003), assim como no auxílio à resolução de complexos problemas de pesquisa (ABRAMO; D'ANGELO; DI COSTA, 2009).

De acordo com Bourdieu (1976) este processo de coautoria revela uma estrutura de relações de poder e de produção, na qual ferramentas de avaliação podem esclarecer razões, indicar tendências, determinar fatores que influenciam a atividade e o capital científico, e revelar uma economia que se desenvolve alicerçada em trocas simbólicas. Assim é que a coautoria vem-se mostrando uma aliada no processo de produtividade de periódicos científicos quando se trata de áreas de pesquisa que possuem um maior nível de especialização ou uma maior quantidade de pesquisadores. Isto porque ela facilita a formação de grupos de pesquisadores com interesses comuns, assim como o acesso livre entre pesquisadores de diferentes campos do conhecimento, de diferentes áreas geográficas, ou que utilizem técnicas e métodos de análise mais sofisticados.

Um outro ponto a favor desta prática é que as pesquisas em coautoria têm maior visibilidade, levando em conta o número de citações que recebem. Ademais, tendem a ser consideradas como de melhor qualidade, tendo em vista que o envolvimento de vários cientistas pode estimular a maturação mais consistente das ideias e maximizar o potencial da produção científica (SILVA et al., 2006).

Laband e Tollison (2000) defendem que a coautoria possui dois principais formatos: a coautoria formal, que envolve participação em grupos de pesquisa, em orientações de teses e dissertações e na produção de artigos; e a coautoria informal, decorrente de discussões com editores, com revisores e com colegas. A coautoria informal abrange aqueles que têm interesses comuns de pesquisa trocando ideias e materiais entre si, também chamados de "colegas invisíveis" (ESPARTEL et al., 2011).

\section{PROCEDIMENTOS METODOLÓGICOS}

O levantamento dos textos a serem analisados foi realizado em duas seções da Divisão Acadêmica Marketing dos Enanpads do triênio 2009-11: Consumo, Cultura e Grupos Sociais, e Cultura e Consumo. A limitação a este período deveu-se, até o evento de 2011, a apenas nele estas seções terem existido.

A opção por este evento enquanto fonte do material deveu-se à sua relevância no contexto acadêmico, no que tange à área de Administração dos Enanpads: o Enanpad é um encontro anual da comunidade científica e acadêmica de Administração, promovido pela Associação Nacional de Pós-Graduação e Pesquisa em Administração (Anpad). Sua primeira edição aconteceu no ano de 1976, o mesmo da criação da associação. Inicialmente formado por representantes dos oito programas de pós-graduação existentes na época no País, o Enanpad reúne 
atualmente mais de 60 representantes de programas de pós-graduação no campo das ciências administrativas, contábeis e afins.

Atualmente o evento é delimitado por 11 Divisões Acadêmicas, divididas por temas de interesse científico, que incluem Administração da Informação; Administração Pública; Contabilidade; Estudos Organizacionais; Ensino e Pesquisa em Administração e Contabilidade; Estratégia em Organizações; Finanças; Gestão de Ciência, Tecnologia e Inovação; Gestão de Operações e Logística; Gestão de Pessoas e Relações de Trabalho; e Marketing. Estas divisões buscam estimular a produção científica e gerar discussões entre pesquisadores, professores e estudantes de pósgraduação das áreas envolvidas no evento.

Para acessar estes artigos, foram consultadas as bases contidas no portal da Anpad e nos anais impressos e eletrônicos dos eventos. Foram selecionados os trabalhos da Divisão Acadêmica Marketing, em particular nas subseções dos temas Consumo, Cultura e Grupos Sociais, e Cultura e Consumo. Este esforço implicou a obtenção de um total de 45 artigos, dos quais 35 tinham mais de um autor. Em seguida à coleta dos dados, fez-se a análise bibliométrica da amostra relativa a nove aspectos de interesse para esta pesquisa: distribuições quantitativa dos trabalhos, de autores por artigo, por gênero de autores, por tipos de coautoria, por ordenação de autores, por forma de coautoria, por tipo de cooperação, e por instituições a que os autores estão afiliados. Todas as informações foram tabuladas, e extraídas as frequências absolutas e relativas de cada quesito em seu ano e em todo o período enfocado. Os resultados foram analisados e as conclusões foram derivadas.

\section{APRESENTAÇÃO E DISCUSSÃO DOS RESULTADOS}

No triênio 2009-11 foram aprovados 2.613 artigos nos Enanpads, sendo 269 artigos na Divisão Acadêmica de Marketing e 45 artigos nas seções de Cultura e Consumo nos anos de 2009 e 2011, e de Consumo, Cultura e Grupos Sociais em 2010 (ver Tabela 1).

\begin{tabular}{|c|c|c|c|c|c|c|c|}
\hline Evento & $\begin{array}{l}\text { Total do } \\
\text { evento }(A)\end{array}$ & $\begin{array}{c}\text { Total da Divisão } \\
\text { de Marketing } \\
\text { (B) }\end{array}$ & $\begin{array}{c}\text { Total das } \\
\text { seções } \\
\text { analisadas (C) }\end{array}$ & $\begin{array}{c}\text { Total dos artigos } \\
\text { com mais de um } \\
\text { autor (D) }\end{array}$ & B/A & C/B & $\mathrm{D} / \mathrm{C}$ \\
\hline Enanpad 2009 & 879 & 88 & 14 & 10 & $10,0 \%$ & $15,9 \%$ & $71,4 \%$ \\
\hline Enanpad 2010 & 854 & 89 & 18 & 16 & $10,4 \%$ & $20,2 \%$ & $88,9 \%$ \\
\hline Enanpad 2011 & 880 & 92 & 13 & 9 & $10,5 \%$ & $14,1 \%$ & $69,2 \%$ \\
\hline Total & 2.613 & 269 & 45 & 35 & $10,3 \%$ & $16,7 \%$ & $77,8 \%$ \\
\hline
\end{tabular}


O que se vê é que os artigos da Divisão Acadêmica de Marketing somaram 10,3\% do total de artigos apresentados nos eventos do triênio, com praticamente nenhuma variação nesta participação a cada ano. Já em se tratando das duas seções avaliadas, no período a representação conjunta foi de $16,7 \%$ dos artigos apresentados na divisão, participação que oscilou entre o mínimo de 14,1\% em 2011 e o máximo de 20,2\% em 2010.

Quanto à avaliação dos aspectos especificamente relacionados à coautoria, ainda na Tabela 1 observa-se que, dos 45 artigos mapeados nas duas seções ao longo de todo o triênio, 35 foram escritos por mais de um autor - ou seja, quase $80 \%$. Também se vê que esta participação variou entre o mínimo de 69,2\% em 2011 e o máximo de praticamente $89 \%$ no ano anterior.

Passando-se ao mapeamento mais detalhado do número de autores por artigo, ao mesmo tempo em que se vê que o número máximo de autores chegou a seis, observa-se que a preferência recaiu sobre a autoria dupla, com 31,1\% das pesquisas, ficando em segundo lugar, empatadas em $22,2 \%$, as opções por um autor e por três autores (ver Tabela 2). Na mesma tabela se verifica que houve relativamente pouco interesse em desenvolver trabalhos com cinco ou seis autores: em conjunto estas duas categorias responsabilizaram-se por não mais do que $11,1 \%$ da amostra.

Aprofundando-se este aspecto no que diz respeito à sua distribuição percentual em cada um dos três eventos, observa-se que, nos Enanpads 2009 e 2010, a maior parte dos artigos foram escritos por dois autores, ao mesmo tempo em que o evento de 2010 foi o único com trabalhos elaborados por cinco autores, e em que, no encontro de 2011, a presença de pesquisas com três autores foi mais do que duas vezes mais intensa do que nos dois outros anos (ver Tabela 3).

Tabela 2 - Enanpads 2009-11 - Quantidade de artigos nas seções Cultura e Consumo em 2009 e em 2011, e Consumo, Cultura e Grupos Sociais em 2010, da Divisão Acadêmica Marketing, categorizados por número de autores, e participação percentual de cada categor

\begin{tabular}{|c|c|c|c|c|c|c|c|}
\hline \multirow{2}{*}{ Evento } & \multicolumn{6}{|c|}{ Número de Autores } & \multirow{2}{*}{$\begin{array}{c}\text { Total de artigos do } \\
\text { evento }\end{array}$} \\
\hline & 1 & 2 & 3 & 4 & 5 & 6 & \\
\hline Enanpad 2009 & 4 & 6 & 2 & 1 & 0 & 1 & 14 \\
\hline Enanpad 2010 & 2 & 6 & 3 & 4 & 2 & 1 & 18 \\
\hline Enanpad 2011 & 4 & 2 & 5 & 1 & 0 & 1 & 13 \\
\hline $\begin{array}{c}\text { Enanpads 2009-11 } \\
\text { Participação }\end{array}$ & 10 & 14 & 10 & 6 & 2 & 3 & 45 \\
\hline $\begin{array}{c}\text { percentual da } \\
\text { categoria no total do } \\
\text { triênio }\end{array}$ & $22,2 \%$ & $31,1 \%$ & $22,2 \%$ & $13,3 \%$ & $4,5 \%$ & $6,7 \%$ & $100 \%$ \\
\hline
\end{tabular}


Tabela 3 - Enanpads 2009-11 - Distribuição percentual dentro de cada evento dos artigos nas seções Cultura e Consumo em 2009 e em 2011, e Consumo, Cultura e Grupos Sociais em 2010, da Divisão Acadêmica Marketing, categorizados por número de autores

\begin{tabular}{|c|c|c|c|c|c|c|c|}
\hline \multirow{2}{*}{ Evento } & \multicolumn{6}{|c|}{ Número de Autores } & \multirow{2}{*}{$\begin{array}{c}\text { Total de artigos do } \\
\text { evento }\end{array}$} \\
\hline & 1 & 2 & 3 & 4 & 5 & 6 & \\
\hline Enanpad 2009 & $28,6 \%$ & $42,9 \%$ & $14,3 \%$ & $7,1 \%$ & $0,0 \%$ & $7,1 \%$ & $100 \%$ \\
\hline Enanpad 2010 & $11,1 \%$ & $33,3 \%$ & $16,7 \%$ & $22,2 \%$ & $11,1 \%$ & $5,6 \%$ & $100 \%$ \\
\hline Enanpad 2011 & $30,8 \%$ & $15,4 \%$ & $38,4 \%$ & $7,7 \%$ & $0,0 \%$ & $7,7 \%$ & $100 \%$ \\
\hline Enanpads 2009-11 & $22,2 \%$ & $31,1 \%$ & $22,2 \%$ & $13,3 \%$ & $4,5 \%$ & $6,7 \%$ & $100 \%$ \\
\hline
\end{tabular}

Fonte: Elaboração própria

Passando-se à análise quantitativa dos autores identificados na autoria de 35 artigos escritos em coautoria, seu total chegou a 110, indicando média de 3,1 autores/artigo (ver Tabela 4). A análise feita para cada evento mostra que as participações oscilaram muito pouco em relação a esta média. Já a distribuição deste total de autores pelos três eventos indica que o Enanpad de 2010 concentrou quase metade deles (ver Tabela 5).

Quando a análise autoral é executada separadamente por gênero, vê-se que praticamente $62 \%$ da amostra de 110 autores foi representada por homens, sendo que sua distribuição ao longo dos três eventos também aponta concentração em 2010 (ver Tabelas 4 e 5). Este último fenômeno também foi observado - e de maneira ainda mais forte - no que tange às autoras femininas.

Tabela 4 - Enanpads 2009-11 - Autores dos artigos dos artigos escritos em coautoria nas seções Cultura e Consumo em 2009 e em 2011, e Consumo, Cultura e Grupos Sociais em 2010, da Divisão Acadêmica Marketing - Totais e divididos por gênero, e quantidades

\begin{tabular}{l|cc|cc|cc}
\multicolumn{1}{c|}{ Evento } & $\begin{array}{c}\text { Total de } \\
\text { autores dos } \\
\text { artigos em } \\
\text { coautoria }\end{array}$ & $\begin{array}{c}\text { Autores/ } \\
\text { artigo }\end{array}$ & $\begin{array}{c}\text { Autores } \\
\text { masculinos }\end{array}$ & $\begin{array}{c}\text { Autoras } \\
\text { femininas }\end{array}$ & $\begin{array}{c}\text { Autores } \\
\text { masculinos/ } \\
\text { artigo }\end{array}$ & $\begin{array}{c}\text { Autoras } \\
\text { femininas/ } \\
\text { artigo }\end{array}$ \\
\hline Enanpad 2009 & 28 & 2,8 & 19 & 9 & 1,9 & 0,9 \\
Enanpad 2010 & 53 & 3,3 & 28 & 25 & 1,8 & 1,6 \\
Enanpad 2011 & 29 & 3,2 & 21 & 8 & 2,3 & 0,9 \\
\hline Enanpads 2009-11 & $\mathbf{1 1 0}$ & $\mathbf{3 , 1}$ & $\mathbf{6 8}$ & $\mathbf{4 2}$ & $\mathbf{1 , 9}$ & $\mathbf{1 , 2}$ \\
\hline
\end{tabular}

Fonte: Elaboração própria 


\section{Tabela 5 - Enanpads 2009-11 - Autores totais e por gênero dos artigos escritos em coautoria nas seções Cultura e Consumo em 2009 e em 2011, e Consumo, Cultura e Grupos Sociais em 2010, da Divisão Acadêmica Marketing - Participações percentuais por categor}

\begin{tabular}{l|ccc}
\multicolumn{1}{c|}{ Evento } & $\begin{array}{c}\text { Distribuição } \\
\text { percentual do } \\
\text { total de } \\
\text { autores }\end{array}$ & $\begin{array}{c}\text { Distribuição } \\
\text { percentual } \\
\text { dos autores } \\
\text { masculinos }\end{array}$ & $\begin{array}{c}\text { Distribuição } \\
\text { percentual } \\
\text { das autoras } \\
\text { femininas }\end{array}$ \\
\hline Enanpad 2009 & $25,4 \%$ & $17,3 \%$ & $8,2 \%$ \\
Enanpad 2010 & $48,2 \%$ & $25,4 \%$ & $22,7 \%$ \\
Enanpad 2011 & $26,4 \%$ & $19,1 \%$ & $7,3 \%$ \\
\hline Enanpads 2009-11 & $\mathbf{1 0 0 \%}$ & $\mathbf{6 1 , 8 \%}$ & $\mathbf{3 8 , 2 \%}$ \\
\hline
\end{tabular}

Fonte: Elaboração própria

Já no que tange à quantidade de autores por artigo especificada por gênero, na média do triênio a participação masculina foi de quase dois autores/artigo, tendo variado relativamente pouco no período (ver Tabela 4). Quanto à participação feminina, ela mal ultrapassou uma autora/artigo no período como um todo, tendo sido mais expressiva em 2010 do que nos dois outros anos.

No que diz respeito aos tipos de colaboração acadêmica em termos de sua origem, quatro análises foram realizadas:

1) Externa internacional: participação simultânea de autores de instituições brasileiras e de terceiros países;

2) Externa nacional: participação simultânea de autores de instituições brasileiras diversas e situadas em estados diferentes;

3) Externa regional: idem, mas no mesmo estado;

4) Interna: participação de autores de uma mesma instituição.

As Tabelas 6 e 7 trazem este levantamento aplicado sobre o número de artigos mapeados em cada evento. O que se verifica é que, para a amostra dos 35 artigos analisados, a preferência recaiu sobre a cooperação interna, com quase $46 \%$ destes trabalhos assim se enquadrando. Em segundo lugar - mas muito distante em relação ao anterior - observa-se que houve preferência pela cooperação externa regional. Em último lugar situou-se a cooperação nacional, inferior até mesmo à externa internacional. 
Tabela 6 - Enanpads 2009-11 - Tipos de cooperação de autoria nos artigos em coautoria nas seções Cultura e Consumo em 2009 e em 2011, e Consumo, Cultura e Grupos Sociais em 2010, da Divisão Acadêmica Marketing - Totais de artigos

\begin{tabular}{|c|c|c|c|c|c|}
\hline \multirow{3}{*}{ Evento } & \multicolumn{5}{|c|}{ Tipos de cooperação } \\
\hline & \multicolumn{3}{|c|}{ Externa } & \multirow{2}{*}{ Interna } & \multirow{2}{*}{$\begin{array}{c}\text { Total dos } \\
\text { tipos }\end{array}$} \\
\hline & Internacional & Nacional & Regional & & \\
\hline Enanpad 2009 & 1 & 0 & 4 & 5 & 10 \\
\hline Enanpad 2010 & 3 & 1 & 4 & 8 & 16 \\
\hline Enanpad 2011 & 1 & 2 & 3 & 3 & 9 \\
\hline Enanpads 2009-11 & 5 & 3 & 11 & 16 & 35 \\
\hline
\end{tabular}

Fonte: Elaboração própria

Olhando-se esta divisão isoladamente por evento, as tendências são um pouco diferentes (ver Tabelas 6 e 7). Por exemplo, em 2009 não houve parceria externa nacional, contrariamente aos anos seguintes. Por outro lado, a cooperação interna, que se manteve em $50 \%$ no biênio $2009-10$, retraiu-se para pouco mais de $30 \%$ no ano de 2011.

Tabela 7 - Enanpads 2009-11 - Tipos de cooperação de autoria nos artigos em coautoria nas seções Cultura e Consumo em 2009 e em 2011, e Consumo, Cultura e Grupos Sociais em 2010, da Divisão Acadêmica Marketing Participações percentuais por evento

\begin{tabular}{|l|c|c|c|c|c|}
\multirow{2}{*}{\multicolumn{1}{c|}{ Evento }} & \multicolumn{3}{|c|}{ Tipos de cooperação } & Total dos \\
\cline { 2 - 4 } & \multicolumn{3}{|c|}{ Externa } & Interna & tipos \\
\cline { 2 - 4 } & Internacional & Nacional & Regional & & $100 \%$ \\
\hline Enanpad 2009 & $10,0 \%$ & $0 \%$ & $40,0 \%$ & $50,0 \%$ & $100 \%$ \\
Enanpad 2010 & $18,7 \%$ & $6,3 \%$ & $25,0 \%$ & $50,0 \%$ & $100 \%$ \\
Enanpad 2011 & $11,1 \%$ & $22,3 \%$ & $33,3 \%$ & $33,3 \%$ & $100 \%$ \\
\hline Enanpads 2009-11 & $14,3 \%$ & $8,6 \%$ & $31,4 \%$ & $45,7 \%$ & $100 \%$ \\
\hline
\end{tabular}

Fonte: Elaboração própria

Passando-se à ordem em que os nomes dos autores são apresentados nos artigos, observaram-se três tendências distintas: 1) ordenação alfabética pelo primeiro nome próprio; 2) ordenação alfabética pelo último sobrenome; e 3) sem definição de ordenação.

No caso da amostra analisada, o que se viu foi que, no triênio como um todo, 21 artigos - ou seja, $60 \%$ do total - optaram por não obedecer uma ordem alfabética nos nomes dos autores (ver Tabela 8). Quanto ao restante da amostra, houve divisão equânime entre a ordenação alfabética do primeiro nome e do último sobrenome. 


\section{Tabela 8 - Enanpads 2009-11 - Tipos de ordenação alfabética dos autores nos artigos em coautoria nas seções Cultura e Consumo em 2009 e em 2011, e Consumo, Cultura e Grupos Sociais em 2010, da Divisão Acadêmica Marketing - Totais e participações pecentua}

\begin{tabular}{|l|c|c|c|c|c|c|}
\multirow{2}{*}{ Evento } & \multicolumn{5}{|c|}{ Tipos de ordenação alfabética dos autores } \\
\cline { 2 - 7 } \multicolumn{1}{c|}{ Primeiro nome } & \multicolumn{2}{c|}{ Último sobrenome } & \multicolumn{2}{c|}{ Sem definição } \\
\cline { 2 - 7 } & Total & $\%$ & Total & $\%$ & Total & $\%$ \\
\hline Enanpad 2009 & 1 & $14,3 \%$ & 3 & $42,8 \%$ & 6 & $28,6 \%$ \\
Enanpad 2010 & 4 & $57,1 \%$ & 2 & $28,6 \%$ & 10 & $47,6 \%$ \\
Enanpad 2011 & 2 & $28,6 \%$ & 2 & $28,6 \%$ & 5 & $23,8 \%$ \\
\hline Enanpads 2009-11 & 7 & $100 \%$ & 7 & $100 \%$ & 21 & $100 \%$ \\
\hline
\end{tabular}

Fonte: Elaboração própria

A mesma análise, mas feita separadamente por evento (ver Tabela 8) mostra que em todos - e com percentuais sempre acima de 50\% - a preferência foi pela ausência de uma definição quanto à ordenação alfabética dos nomes dos autores. Quanto às duas outras formas, no evento de 2009 foi mais usado o último sobrenome, o uso do primeiro nome foi mais usado no ano de 2010, e no evento de 2011 houve divisão equânime entre estas duas opções.

A análise da amostra também envolveu as formas de coautoria, entendidas como a participação docente e discente na autoria dos trabalhos. Para tanto, utilizouse como fonte de pesquisa a Plataforma Lattes e levou-se em conta a condição ali informada do autor na época da publicação do artigo.

Os resultados mostraram que praticamente $83 \%$ dos trabalhos foram elaborados a partir do esforço conjunto de docentes e discentes, com números muito pequenos no que tange aos outros dois tipos de composição de autores (ver Tabela 9). A análise de cada um dos eventos mostra que esta tendência a priorizar o trabalho conjunto de professores e de alunos foi muito aguda em 2010: dos 16 trabalhos das seções enfocadas e que traziam mais de um autor, nada menos que 15 resultaram deste tipo de parceria, ao mesmo tempo em que não houve nenhum artigo assinado apenas por docentes.

Por outro lado, também se vê que, ao longo do triênio, a apresentação de trabalhos em coautoria apenas de alunos não ultrapassou a unidade, representando menos de $10 \%$ da amostra de 35 artigos.

Tabela 9 - Enanpads 2009-11 - Quantidade de artigos nas seções Cultura e Consumo em 2009 e em 2011, e Consumo, Cultura e Grupos Sociais em 2010, da Divisão Acadêmica Marketing, por origem docente e discente

\begin{tabular}{|c|c|c|c|c|c|c|c|c|}
\hline \multirow[b]{2}{*}{ Evento } & \multicolumn{8}{|c|}{ Tipo de produção } \\
\hline & $\begin{array}{c}\text { Produção apenas } \\
\text { discente }\end{array}$ & $\%$ & $\begin{array}{c}\text { Produção docente e } \\
\text { discente }\end{array}$ & $\%$ & $\begin{array}{c}\text { Produção } \\
\text { apenas } \\
\text { docente }\end{array}$ & $\%$ & $\begin{array}{l}\text { Total dos } \\
\text { três tipos }\end{array}$ & $\%$ \\
\hline Enanpad 2009 & 1 & $10,0 \%$ & 6 & $60,0 \%$ & 3 & $30,0 \%$ & 10 & $100 \%$ \\
\hline Enanpad 2010 & 1 & $6,3 \%$ & 15 & $93,8 \%$ & 0 & $0,0 \%$ & 16 & $100 \%$ \\
\hline Enanpad 2011 & 1 & $11,1 \%$ & 8 & $88,9 \%$ & 0 & $0,0 \%$ & 9 & $100 \%$ \\
\hline Enanpads 2009-11 & 3 & $8,6 \%$ & 29 & $82,8 \%$ & 3 & $8,6 \%$ & 35 & $100 \%$ \\
\hline
\end{tabular}

Fonte: Elaboração própria 
Passando-se à distribuição das instituições de afiliação dos autores da amostra de 35 artigos, inicialmente vale destacar dois pontos:

1) No que se refere aos discentes, consideraram-se aquelas de afiliação mencionadas na produção do artigo, independente de outras instituições referidas em seus currículos Lattes; no que se refere aos docentes, consideraram-se todas aquelas de afiliação mencionadas nos anais pesquisados.

2) Como, portanto, um docente autor pode se revelar afiliado a mais do que apenas uma instituição, isto implica que o somatório de afiliações não raro ultrapassa o número referido à contagem dos autores de uma amostra de artigos.

Em consequência, para o total de 110 autores identificados nos artigos escritos em coautoria foram identificadas 119 afiliações, relativas a 30 instituições (ver Tabela 10).

Por outro lado, dentre as instituições identificadas, uma referia-se ao Instituto Nacional de Propriedade Intelectual (INPI), autarquia federal não enquadrada como entidade educacional, e três referiam-se a escolas estrangeiras (Universidad Nacional de Missiones, Rice University e Reims Management School). Portanto, depurando-se a lista para apenas as instituições educacionais brasileiras, chega-se ao total de 26 escolas e de 111 afiliações (ver Tabela 11).

Nesta fitragem verifica-se que a maior diversidade de afiliações ocorreu no ano de 2010, com 51 representações, enquanto os dois outros anos apresentaram 30 representações cada (ver Tabela 11). A instituição educacional cujos afiliados destacaram-se na amostra estudada foi a Universidade Federal do Rio Grande do Sul (UFRGS): sozinha, ela respondeu por quase $22 \%$ do total identificado. Em segundo lugar, com praticamente $10 \%$, situou-se a Universidade Federal do Rio de Janeiro (UFRJ). 


\begin{tabular}{|c|c|c|c|c|c|}
\hline & & \multicolumn{3}{|c|}{ ENANPAD } & \multirow[b]{2}{*}{ TOTAL } \\
\hline & INSTITUIÇÃO & 2009 & 2010 & 2011 & \\
\hline 1 & UNIVERSIDADE FEDERAL DO RIO GRANDE DO SUL - UFRGS & 1 & 15 & 8 & 24 \\
\hline 2 & UNIVERSIDADE FEDERAL DO RIO DE JANEIRO - UFRJ & 1 & 7 & 3 & 11 \\
\hline 3 & PONTIFICIA UNIVERSIDADE CATOLICA DO RIO DE JANEIRO - PUC RIO & 3 & 1 & $\frac{5}{5}$ & 9 \\
\hline & UNIVERSIDADE REGIONAL DO NOROESTE DO ESTADO DO RIO GRANDE DO SUL - UNIJUI & 5 & 4 & & 9 \\
\hline 5 & PONTIFÍCIA UNIVERSIDADE CATÓLICA DO RIO GRANDE DO SUL - PUC RS & 4 & 4 & & 8 \\
\hline & UNIVERSIDADE DE SÄO PAULO - USP & & 7 & 1 & 8 \\
\hline 7 & UNIVERSIDADE FEDERAL DE MINAS GERAIS - UFMG & 4 & & 4 & 8 \\
\hline 8 & UNIVERSIDADE FEDERAL DE PERNAMBUCO - UFPE & 1 & & 3 & 4 \\
\hline 9 & UNIVERSIDAD NACIONAL DE MISSIONES - UNaM & 3 & 1 & & 4 \\
\hline 10 & UNIVERSIDADE FEDERAL DO PARANA - UFPR & & 3 & & 3 \\
\hline 11 & FUNDAÇÃO GETÚLIO VARGAS - FGV RJ & 2 & 1 & & 3 \\
\hline 12 & FUNDAÇÃO GETÚLIO VARGAS - FGV SP & $\frac{5}{2}$ & & 1 & $\frac{5}{3}$ \\
\hline 13 & ESCOLA SUPERIOR DE PROPAGANDA E MARKETING - ESPM SP & 1 & & 1 & 2 \\
\hline 14 & INSTITUTO DE ENSINO E PESQUISA - INSPER SP & 2 & & & 2 \\
\hline 15 & UNIVERSIDADE FEDERAL DO ESPIRITO SANTO - UFES & & 2 & & $\frac{2}{2}$ \\
\hline 16 & UNIVERSIDADE ESTÁCIO DE SÁ - UNESA RJ & & 2 & & 2 \\
\hline 17 & UNIVERSIDADE DO GRANDE RIO - UNIGRANRIO & & 2 & & 2 \\
\hline 18 & RICE UNIVERSITY - USA & & 2 & & $\frac{2}{2}$ \\
\hline & UNIVERSIDADE DO NORTE DO PARANÁ - UNOPAR & & 1 & 1 & 2 \\
\hline 20 & ESCOLA SUPERIOR DE PROPAGANDA E MARKETING - ESPM RJ & 1 & & & 1 \\
\hline 21 & ESCOLA SUPERIOR DE PROPAGANDA E MARKETING - ESPM RS & & 1 & & 1 \\
\hline 22 & FACULDADE DE BOA VIAGEM - FBV & 1 & & & 1 \\
\hline 23 & INSTITUTO NACIONAL DE PROPRIEDADE INDUSTRIAL - INPI RJ & & & 1 & 1 \\
\hline 24 & REIMS MANAGEMENT SCHOOL - RMS FRANCE & & & 1 & 1 \\
\hline 25 & UNIVERSIDADE FEDERAL RURAL DO RIO DE JANEIRO - UFRRJ & & & 1 & 1 \\
\hline 26 & UNIVERSIDADE FEDERAL DE SANTA CATARINA - UFSC & & 1 & & 1 \\
\hline 27 & UNIVERSIDADE FEDERAL DE SÄO JOÃO DEL REY - UFSJ & & & 1 & 1 \\
\hline 28 & PONTIFICIA UNIVERSIDADE CATÓLICA DE MINAS GERAIS - PUC MG & 1 & & & 1 \\
\hline 29 & UNIVERSIDADE ESTADUAL DE MARINGÁ - UEM & 1 & & & 1 \\
\hline \multirow{2}{*}{$\begin{array}{l}29 \\
30\end{array}$} & UNIVERSIDADE FEDERAL DE SANTA MARIA - UFSM & & & 1 & 1 \\
\hline & & 33 & 54 & 32 & 119 \\
\hline
\end{tabular}

No outro extremo (ver Tabela 11), as instituições brasileiras com apenas um autor participante na amostra estudada foram quatro universidades federais (Rural do Rio de Janeiro, de Santa Catarina, de São João del Rey e de Santa Maria), uma estadual (de Maringá) e três particulares (Pontifícia Universidade Católica de Minas Gerais, Escola Superior de Propaganda e Marketing, e Faculdade de Boa Viagem).

\begin{tabular}{|c|c|c|c|c|c|c|}
\hline & \multirow[b]{2}{*}{ INSTITUIÇÃO } & \multicolumn{3}{|c|}{ ENANPAD } & \multirow[b]{2}{*}{ TOTAL } & \multirow[b]{2}{*}{$\%$} \\
\hline & & 2009 & 2010 & 2011 & & \\
\hline 1 & UNIVERSIDADE FEDERAL DO RIO GRANDE DO SUL - UFRGS & 1 & 15 & 8 & 24 & $21,6 \%$ \\
\hline 2 & UNIVERSIDADE FEDERAL DO RIO DE JANEIRO - UFRJ & 1 & 7 & 3 & 11 & $9,9 \%$ \\
\hline 3 & PONTIFICIA UNIVERSIDADE CATÓLICA DO RIO DE JANEIRO - PUC RIO & 3 & 1 & 5 & 9 & $8,1 \%$ \\
\hline 4 & UNIVERSIDADE REGIONAL DO NOROESTE DO ESTADO DO RIO GRANDE DO SUL - UNIJUÍ & 5 & 4 & & 9 & $8,1 \%$ \\
\hline 5 & PONTIFICIA UNIVERSIDADE CATÓLICA DO RIO GRANDE DO SUL - PUC RS & 4 & 4 & & 8 & $7,2 \%$ \\
\hline 6 & UNIVERSIDADE DE SÃO PAULO - USP & & 7 & 1 & 8 & $7,2 \%$ \\
\hline 7 & UNIVERSIDADE FEDERAL DE MINAS GERAIS - UFMG & 4 & & 4 & 8 & $7,2 \%$ \\
\hline 8 & UNIVERSIDADE FEDERAL DE PERNAMBUCO - UFPE & 1 & & 3 & 4 & $3,6 \%$ \\
\hline 9 & UNIVERSIDADE FEDERAL DO PARANÁ - UFPR & & 3 & & 3 & $2,7 \%$ \\
\hline 10 & FUNDAÇÃO GETÚLIO VARGAS - FGV RJ & 2 & 1 & & 3 & $2,7 \%$ \\
\hline 11 & FUNDAÇÃO GETÚLIO VARGAS - FGV SP & 2 & & 1 & 3 & $2,7 \%$ \\
\hline 12 & ESCOLA SUPERIOR DE PROPAGANDA E MARKETING - ESPM SP & 1 & & 1 & 2 & $1,8 \%$ \\
\hline 13 & INSTITUTO DE ENSINO E PESQUISA - INSPER SP & 2 & & & 2 & $1,8 \%$ \\
\hline 14 & UNIVERSIDADE FEDERAL DO ESPÍRITO SANTO - UFES & & 2 & & 2 & $1,8 \%$ \\
\hline 15 & UNIVERSIDADE ESTÁCIO DE SÁ - UNESA RJ & & 2 & & 2 & $1,8 \%$ \\
\hline 16 & \begin{tabular}{|l|} 
UNIVERSIDADE DO GRANDE RIO - UNIGRANRIO \\
\end{tabular} & & 2 & & 2 & $1,8 \%$ \\
\hline 17 & UNIVERSIDADE DO NORTE DO PARANÁ - UNOPAR & & 1 & 1 & 2 & $1,8 \%$ \\
\hline 18 & ESCOLA SUPERIOR DE PROPAGANDA E MARKETING - ESPM RJ & 1 & & & 1 & $0,9 \%$ \\
\hline 19 & ESCOLA SUPERIOR DE PROPAGANDA E MARKETING - ESPM RS & & 1 & & 1 & $0,9 \%$ \\
\hline 20 & FACULDADE DE BOA VIAGEM - FBV & 1 & & & 1 & $0,9 \%$ \\
\hline 21 & UNIVERSIDADE FEDERAL RURAL DO RIO DE JANEIRO - UFRRJ & & & 1 & 1 & $0,9 \%$ \\
\hline 22 & UNIVERSIDADE FEDERAL DE SANTA CATARINA - UFSC & & 1 & & 1 & $0,9 \%$ \\
\hline 23 & UNIVERSIDADE FEDERAL DE SÃO JOÂO DEL REY - UFS J & & & 1 & 1 & $0,9 \%$ \\
\hline 24 & PONTIFICIA UNIVERSIDADE CATÓLICA DE MINAS GERAIS - PUC MG & 1 & & & 1 & $0,9 \%$ \\
\hline 25 & UNIVERSIDADE ESTADUAL DE MARINGÁ - UEM & 1 & & & 1 & $0,9 \%$ \\
\hline \multirow[t]{2}{*}{26} & UNIVERSIDADE FEDERAL DE SANTA MARIA - UFSM & & & 1 & 1 & $0,9 \%$ \\
\hline & & 30 & 51 & 30 & 111 & $100 \%$ \\
\hline
\end{tabular}


No que diz respeito à distribuição regional das escolas às quais os autores da amostra encontravam-se afiliados, o que se verifica é que, conjuntamente, as regiões sudeste e sul responsabilizaram-se por quase $96 \%$ das afiliações, ficando a região nordeste com o restante (ver Tabela 12).

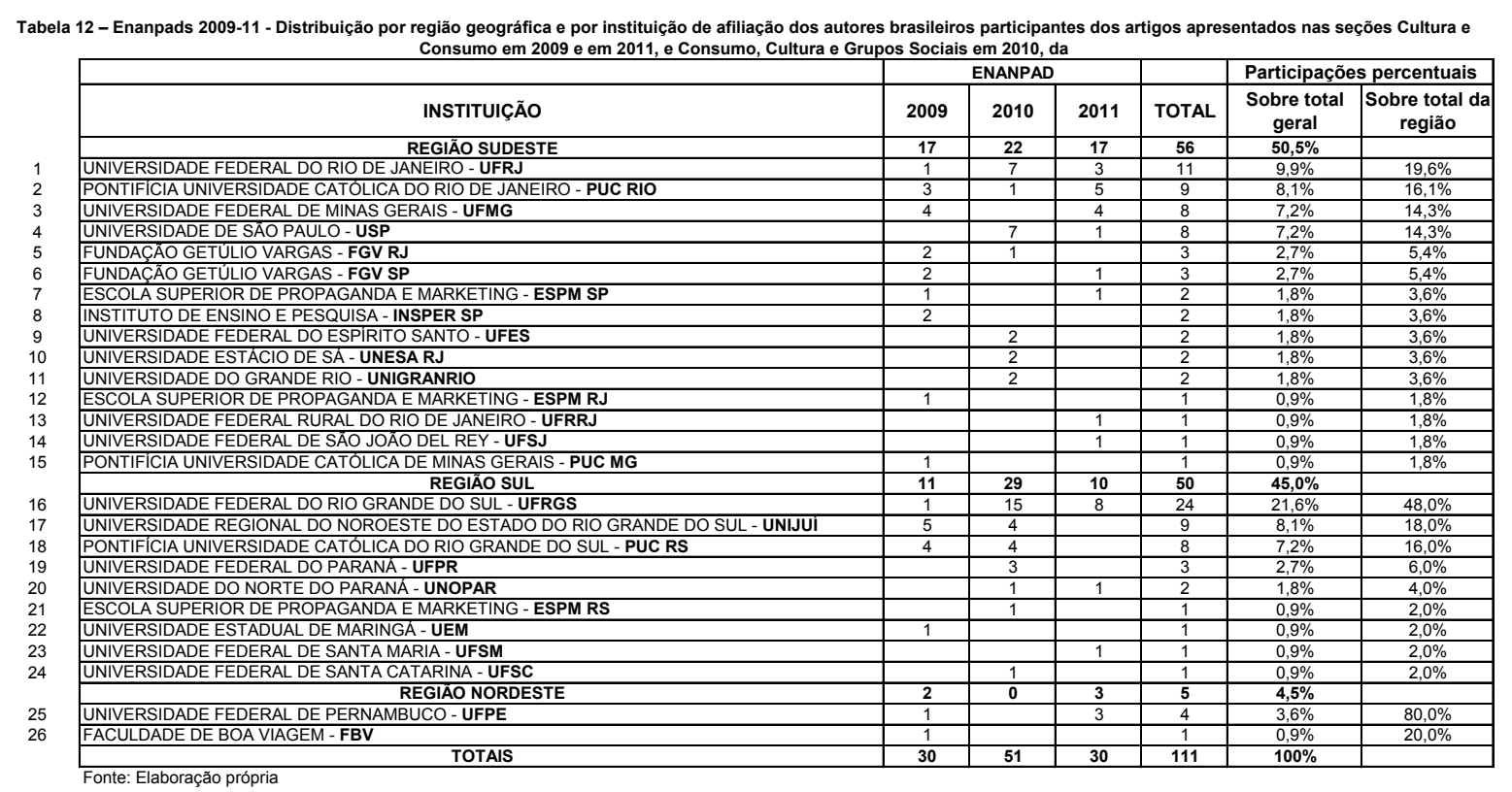

Quanto à representatividade das escolas dentro de cada região, no caso do Sudeste pouco mais de $64 \%$ ficaram por conta de apenas quatro escolas: a UFRJ, a Pontifícia Universidade Católica do Rio de Janeiro (PUC- Rio), a Universidade Federal de Minas Gerais (UFMG) e a Universidade de São Paulo (USP). Já no caso do Sul, a UFRGS isoladamente responsabilizou-se por $48 \%$ das afiliações, e, no Nordeste, a Universidade Federal de Pernambuco (UFPE) ficou com $80 \%$ da representatividade regional (ver Tabela 12). 


\begin{tabular}{|c|c|c|c|c|c|c|}
\hline & \multirow[b]{2}{*}{ INSTITUIÇÃO } & \multicolumn{3}{|c|}{ ENANPAD } & \multirow[b]{2}{*}{ TOTAL } & \multirow[b]{2}{*}{$\begin{array}{c}\% \text { sobre tota } \\
\text { geral }\end{array}$} \\
\hline & & 2009 & 2010 & 2011 & & \\
\hline 1 & UNIVERSIDADE FEDERAL DO RIO DE JANEIRO - UFRJ & 1 & 7 & 3 & 11 & $9,9 \%$ \\
\hline 2 & UNIVERSIDADE FEDERAL DE MINAS GERAIS - UFMG & 4 & & 4 & 8 & $7,2 \%$ \\
\hline 3 & UNIVERSIDADE DE SÃO PAULO - USP & & 7 & 1 & 8 & $7,2 \%$ \\
\hline 4 & UNIVERSIDADE FEDERAL DO ESPIRITO SANTO - UFES & & 2 & & 2 & $1,8 \%$ \\
\hline 5 & UNIVERSIDADE FEDERAL RURAL DO RIO DE JANEIRO - UFRRJ & & & 1 & 1 & $0,9 \%$ \\
\hline 6 & UNIVERSIDADE FEDERAL DE SÄO JOÄO DEL REY - UFS J & & & 1 & 1 & $0,9 \%$ \\
\hline 7 & UNIVERSIDADE FEDERAL DO RIO GRANDE DO SUL - UFRGS & 1 & 15 & 8 & 24 & $21,6 \%$ \\
\hline 8 & UNIVERSIDADE FEDERAL DO PARANÁ - UFPR & & 3 & & 3 & $2,7 \%$ \\
\hline 9 & UNIVERSIDADE ESTADUAL DE MARINGÁ - UEM & 1 & & & 1 & $0,9 \%$ \\
\hline 10 & UNIVERSIDADE FEDERAL DE SANTA MARIA - UFSM & & & 1 & 1 & $0,9 \%$ \\
\hline 11 & UNIVERSIDADE FEDERAL DE SANTA CATARINA - UFSC & & 1 & & 1 & $0,9 \%$ \\
\hline \multirow[t]{2}{*}{12} & UNIVERSIDADE FEDERAL DE PERNAMBUCO - UFPE & 1 & & 3 & 4 & $3,6 \%$ \\
\hline & TOTAL INSTITUIÇỎES PÚBLICAS & 8 & 35 & 22 & 65 & $58,6 \%$ \\
\hline 13 & PONTIFICIA UNIVERSIDADE CATÓLICA DO RIO DE JANEIRO - PUC RIO & 3 & 1 & 5 & 9 & $8,1 \%$ \\
\hline 14 & FUNDAÇÃO GETÚLIO VARGAS - FGV RJ & 2 & 1 & & 3 & $2,7 \%$ \\
\hline 15 & FUNDAÇÁO GETÚLIO VARGAS - FGV SP & 2 & & 1 & 3 & $2,7 \%$ \\
\hline 16 & ESCOLA SUPERIOR DE PROPAGANDA E MARKETING - ESPM SP & 1 & & 1 & 2 & $1,8 \%$ \\
\hline 17 & INSTITUTO DE ENSINO E PESQUISA - INSPER SP & 2 & & & 2 & $1,8 \%$ \\
\hline 18 & UNIVERSIDADE ESTÁCIO DE SÁ - UNESA RJ & & 2 & & 2 & $1,8 \%$ \\
\hline 19 & UNIVERSIDADE DO GRANDE RIO - UNIGRANRIO & & 2 & & 2 & $1,8 \%$ \\
\hline 20 & ESCOLA SUPERIOR DE PROPAGANDA E MARKETING - ESPM RJ & 1 & & & 1 & $0,9 \%$ \\
\hline 21 & PONTIFICIA UNIVERSIDADE CATOLICA DE MINAS GERAIS - PUC MG & 1 & & & 1 & $0,9 \%$ \\
\hline 22 & UNIVERSIDADE REGIONAL DO NOROESTE DO ESTADO DO RIO GRANDE DO SUL - UNIJUÍ & 5 & 4 & & 9 & $8,1 \%$ \\
\hline 23 & \begin{tabular}{|l} 
PONTIFICIA UNIVERSIDADE CATÓLICA DO RIO GRANDE DO SUL - PUC RS \\
\end{tabular} & 4 & 4 & & 8 & $7,2 \%$ \\
\hline 24 & UNIVERSIDADE DO NORTE DO PARANÁ - UNOPAR & & 1 & 1 & 2 & $1,8 \%$ \\
\hline 25 & ESCOLA SUPERIOR DE PROPAGANDA E MARKETING - ESPM RS & & 1 & & 1 & $0,9 \%$ \\
\hline \multirow[t]{3}{*}{26} & FACULDADE DE BOA VIAGEM - FBV & 1 & & & 1 & $0,9 \%$ \\
\hline & TOTAL INSTITUIÇŌES PRIVADAS & 22 & 16 & 8 & 46 & $41,4 \%$ \\
\hline & TOTAIS & 30 & 51 & 30 & 111 & $100,0 \%$ \\
\hline
\end{tabular}

\section{CONSIDERAÇÕES FINAIS}

Este levantamento bibliométrico apontou que, no triênio 2009-11, nas seções Consumo, Cultura e Grupos Sociais, e Cultura e Consumo dos Enanpads houve 35 artigos escritos em coautoria, num total de 110 participantes destes trabalhos. Suas características mais relevantes, de uma forma geral, foram:

1) Estes 35 artigos equivaleram a quase $80 \%$ de todos os artigos das duas seções analisadas;

2) A preferência pela quantidade de participantes foi de dois autores, a média da amostra foi de 3,1 autores/artigo, e o máximo de participantes verificado foi de seis autores;

3) Os autores masculinos somaram 62\% dos 110 autores identificados;

4) Quase metade da amostra revelou coautoria em nível de cooperação interna, entendida como participantes pertencentes a uma mesma instituição, enquanto a cooperação nacional (participantes pertencentes a instituições diversas dentro do Brasil) foi inferior até mesmo à externa internacional;

5) A ordenação dos nomes dos autores nos artigos não obedeceu a nenhum critério específico em $60 \%$ da amostra;

6) Mais de $80 \%$ da amostra foi elaborada a partir do esforço conjunto de docentes e discentes; 
7) As afiliações dos autores foi verificada, em maior grau, junto a instituições públicas, com destaque para a UFRGS, localizadas quase que totalmente nas regiões sul e sudeste do País; e

8) A colaboração docente-discente foi mais intensa nas instituições públicas do que nas particulares.

Vê-se, primeiramente, que a coautoria é um evento assaz costumeiro no que tange aos trabalhos de Marketing que versem sobre consumo com foco em cultura e em grupos sociais, e que tenham sido apresentados em anos recentes no mais importante evento da área de Administração de Empresas no Brasil. Trata-se de fato relevante, tendo em vista que a cooperação acadêmica costuma trazer benefícios evidentes à pesquisa, a partir das externalidades positivas geradas pelo compartilhamento e pela troca de informações entre pesquisadores. Isto ocorre conforme seus achados são discutidos conjuntamente pela associação da produção de várias origens a partir do interesse coletivo de diferentes pesquisadores em temas específicos (GRAEML; MACADAR, 2010).

Outra descoberta alvissareira é que mais de $80 \%$ da amostra tenha sido elaborada a partir do esforço conjunto de docentes e discentes. Mesmo considerandose que este tipo de parceria pelo menos em parte estaria obedecendo à regra de produção de artigo(s) derivado(s) de orientações em cursos de mestrado e de doutorado, não deixa de ser digno de nota que este esforço tem rendido frutos de qualidade, tendo em vista sua aceitação em evento de renome nacional.

Uma terceira descoberta digna de nota é que as afiliações dos autores tenha sido verificada, em maior grau, junto a instituições públicas. Isto evidencia a seriedade do trabalho dos pesquisadores das escolas mantidas pela sociedade, indicando o bom aproveitamento dos recursos públicos que esta última lhes direciona.

Por outro lado, outros achados deste levantamento revelam-se preocupantes, que parecendo indicar vícios existentes na prática da coautoria.

Pode-se destacar, por exemplo, o fato de quase metade da amostra ter revelado coautoria em nível de cooperação interna, ficando a cooperação nacional em nível inferior até mesmo à externa internacional. Em outras palavras, a interação interinstituições foi muito fraca, o que poderia denunciar o desinteresse dos docentes em interagir com seus pares de outras escolas.

Outro dado revelador é que, na amostra analisada, a preferência pela quantidade de participantes/artigo tenha sido de apenas dois autores. Partindo-se do princípio que a participação dos autores tenha ocorrido a partir de uma real colaboração de cada um à pesquisa, fica a impressão de que aqueles benefícios evidentes à pesquisa trazidos pela cooperação acadêmica estariam ocorrendo em nível subótimo conforme se beneficiam de não mais do que apenas duas formas de pensar. 
Ainda em termos de descobertas perturbadoras, tem-se o reverso da moeda relativo ao grande peso das instituições públicas na amostra: a menor representatividade das instituições privadas. Trata-se de elemento que sugere reflexão, tendo em vista que os pesquisadores - de escolas tanto públicas quanto privadas - são avaliados trianualmente por sua produção acadêmica. Isto, em princípio, levaria a se esperar produção ainda mais intensa das escolas privadas, onde o corpo docente não conta com a estabilidade da instituição pública. Como foi visto, pelo menos na amostra estudada, tal não ocorreu. A causa para tanto não foi objeto de verificação nesta pesquisa, mas podem-se lançar suposições a respeito. Poderia ser tão somente uma consequência da pequena quantidade de trabalhos avaliados, mas também poderia derivar de as escolas particulares não estarem sabendo utilizar um eventual "bom corporativismo" representado pelo hábito de, mesmo sem nenhuma colaboração, os docentes convidarem seus pares à participação em seus trabalhos como forma de alavancar a produção acadêmica conjunta.

Como último ponto, vale destacar o grande limitador deste trabalho, que é o pequeno tamanho da amostra estudada. Contorná-lo seria difícil porquanto seções ligadas simultaneamente a cultura e a consumo na Divisão Acadêmica Marketing do Enanpad, até o ano de 2011, só foram observadas no triênio analisado.

Sugestões para futuros estudos englobam a pesquisa de outros aspectos bibliométricos dos artigos desta amostra, tais como tipos utilizados de abordagem, seus meios e suas finalidades. Também se sugere que outras pesquisas estudem as cocitações - citações recíprocas envolvendo pares em estudos na mesma linha de pesquisa - enquanto forma de se analisarem longitudinalmente as mudanças nas estruturas intelectuais e nas características de um campo de estudo.

\section{REFERÊNCIAS}

ABRAMO, G.; D'ANGELO, C.; DI COSTA, F. Research collaboration and productivity: is there correlation? Higher Education, 57(2), 155-171, 2009.

ACEDO, F.; BARROSO, C.; CASANUEVA, C.; GALÁN, J. Co-Authorship in Management and Organizational Studies: An Empirical and Network Analysis. Journal of Management Studies, 43:5, July 2006.

ANPAD - Associação Nacional de Pós-Graduação e Pesquisa em Administração. Disponível em <http://www.anpad.org.br>. Acesso em 20 mai 2012.

ARAÚJO, R.; ALVARENGA, L. A bibliometria na pesquisa científica da pósgraduação brasileira de 1987 a 2007. Revista Eletrônica de Bibliotecononomia, v. 16, n. 31, p.51-70, 2011. 
BELK, R. Possessions and the Extended Self. Journal of Consumer Research, v.15, p.139-168, sept., 1988.

BLACKWELL, R.; MINIARD, P.; ENGEL, J. Comportamento do Consumidor. São Paulo: Thompson, 2005.

BOURDIEU, P. Le champ scientifique. Actes de la Recherche em Sciences Sociales, [Lyon], v. 2, n. 2/3, p. 88-104, jun. 1976.

CASTILHOS, R.; ROSSI, C.; CAVEDON, N. Cultura e Consumo de Famílias no Brasil e na França. XXIX Encontro da ANPAD (Enanpad). Anais... São Paulo (SP), 2005.

COBRA, M. Administração de Marketing. São Paulo: Atlas, 2ª Ed., 2005.

DIAS, S. Gestão de Marketing: professores do departamento de mercadologia da FGVEAESP e convidados. São Paulo: Saraiva, 2003.

DOUGLAS, M.; ISHERWOOD, B. O mundo dos bens. Rio de Janeiro: UFRJ, 2004.

ENANPAD - Encontro Nacional dos Programas de Pós-Graduação em Administração, 2011. Disponível em: http://www.anpad.org.br.

ESPARTEL, L.; BASSO, K.; TOMAZELLI, J.; CALLEGARO, A.; VISENTINI; M. CoAutoria em Ensino e Pesquisa em Administração e Contabilidade no Brasil: Uma Década em Análise. Revista de Administração Imed, vol. 1, n. 1, p. 01-28, dez., 2011.

GONÇALVES, S. Cultura e Sociedade de Consumo: um olhar em retrospecto. inRevista, ano 3, n. 5, p. 18-28, 2008.

GOSNELL, C. Obsolescence of books in college libraries. College and Research Libraries (Chicago), vol. 5, n. 2, p. 115-125, March, 1944.

GRAEML, A.; MACADAR, M. Análise de Citações Utilizadas em ADI: 10 anos de anais digitais do Enanpad (1997-2006). Revista de Administração Contemporânea, v. 14, n. 1, p. 122-148, 2010.

HAYASHI, M.; HAYASHI, C.; SILVA, M.; LIMA, M. Um estudo bibliométrico da produção científica sobre a educação jesuítica no Brasil colonial. Biblios, ano 8, n. 27, 2007. 
HULME, E. Statistical Bibliography In Relation to the Growth of Modern Civilization: Two Lectures Delivered in the University of Cambridge in May 1922. London: Grafton, 1922.

KEEGAN, W.; GREEN, M. Princípios de Marketing Global. São Paulo: Saraiva, 2003.

LABAND, D. N.; TOLLISON, Robert D. Intellectual Collaboration. The Journal of Political Economy, V.108, n.3, Jun 2000.

LARAIA, R. Cultura: um conceito antropológico. Rio de Janeiro: Jorge Zahar, 2000.

LETA, J.; CRUZ, C. A produção científica brasileira. In: VIOTTI, E.; MACEDO, M. Indicadores de ciência, tecnologia e inovação no Brasil. Campinas: Unicamp, 2003.

LOTKA, A. J. The frequency of distribuition of scientific productivity. Journal of the Washington Academy of Sciences, v.16, n.12, p.317-323, 1926.

MACHADO, M.; PEREIRA, S. Espelho, Espelho Meu, Quem Sou Eu? Consumo Estético e a Construção da Identidade da Mulher. IV Encontro de Marketing da ANPAD (EMA). Anais... Florianópolis (SC), maio, 2010.

MAIA, M.; CAREGNATO, S. Coautoria como indicador de redes de colaboração científica. Perspectivas em Ciência da Informação, vol. 13, n. 2, p. 18-31, maio-ago., 2008.

MEADOWS, A. A comunicação científica. Brasília: Briquet de Lemos, 1999.

MUGNAINI, R.; JANNUZZI, P.; QUONIAM, L. Indicadores bibliométricos da produção científica brasileira: uma análise a partir da base Pascal. Ci. Inf., v. 33, n. 2, p. 123-131, maio/ago., 2004.

OTLET, P. El Tratado de Documentación: el libro sobre el libro: teoría y práctica. Trad. por Maria Dolores Ayuso García. Murcia: Universidad de Murcia, 1996. Tradução de: Traité de Documentation: le livre sur le livre: théorie et pratique. Bruxelles: Mundaneum, 1934, p. 431.

PENA, B.; COUTINHO, F.; PÉPECE, O. O Que Devo Comer? Influência da Cultura no Comportamento de Consumo de Alimentos por Gestantes. V Encontro Nacional de Estudos do Consumo I Encontro Luso-Brasileiro de Estudos do Consumo 
Tendências e Ideologias do Consumo no Mundo Contemporâneo (ENEC). Anais... Rio de Janeiro (RJ), setembro, 2010.

PIZZANI, L.; DA SILVA, R.; HOSSNE, W. Análise bibliométrica dos 40 anos da produção científica em Bioética no Brasil e no mundo. Revista Bioethikos, vol. 4, n. 4, p. 453-460, 2010.

PRITCHARD, A. Statistical bibliography or bibliometrics? Journal of documentation, v.25, n.4, p.348-349, Dec., 1969.

RAISING, L. Statistical Bibliography in the health science. Bulletin of the Medical Library Association, vol. 50, n. 3, p. 450-61, 1962.

ROCHA, E. Culpa e prazer: imagens do consumo na cultura de massa. Comunicação, Mídia e Consumo, vol. 2, n. 3, p. 123-138, 2005.

RUSCHEINSKY, A. Consumo, prática social e movimentos sociais na sociedade complexa. II Seminário Nacional Movimentos Sociais, Participação e Democracia. Anais... Florianópolis (SC), abril, 2007.

SCHIFFMAN L.; KANUK, L. Comportamento do consumidor. Rio de Janeiro: LTC, 2009.

SILVA, A.; MATHEUS, R.; PARREIRAS, F.; PARREIRAS, T. Estudo da rede de coautoria e da interdisciplinaridade na produção científica com base nos métodos de análise de redes sociais: avaliação do caso do programa de pós-graduação em ciência da informação - PPGCI / UFMG. Encontros Bibli, UFSC, n. 1, p. 179-194, 2006.

SPLITTER,K.; ROSA, C.; BORBA, J. Uma Análise das Características dos Trabalhos "Ditos" Bibliométricos Publicados no Enanpad entre 2000 e 2011. XXXVI Encontro da ANPAD. Anais... Rio de Janeiro (RJ), setembro, 2012.

TAYLOR, E. Primitive culture: researches into the development of mythology, philosophy, religion, art, and custom. London: John Murray, $4^{\text {th }}$ ed., 1903. 